\title{
REFLEXÕES SOBRE OS DIREITOS HUMANOS DO BEM VIVER: O NOVO CONSTITUCIONALISMO LATINO-AMERICANO A PARTIR DE UM DOS SEUS FUNDAMENTOS.
}

\section{Marcos Leite Garcia ${ }^{1}$}

RESUMO: Esta pesquisa tem como objeto de estudo o fenômeno do bem viver, bien vivir ou buen vivir. É preciso identificar e conceituar um dos principais fundamentos da construção do Novo Constitucionalismo Latino-Americano. Assim, a reflexão parte de duas perguntas essenciais para a teoria do Novo Constitucionalismo Latino-Americano, em primeiro lugar: o que é o bem viver? E em segundo lugar: quais são os direitos humanos do bem viver? O objetivo geral é fazer algumas reflexões sobre o bem viver, determinar os Direitos Humanos do bem viver. $\mathrm{O}$ método utilizado na fase de investigação foi o Indutivo.

PALAVRAS-CHAVE: Bem viver; Direitos Humanos; Constitucionalismo; América Latina; Fundamentos.

\section{REFLECTIONS ON THE HUMAN RIGTHTS OF THE WELL LIVE: THE NEW LATIN AMERICAN CONSTITUTIONALISM FROM ONE OF ITS FOUNDATIONS}

ABSTRACT: This research has as object of study the phenomenon of well living or good living. It is necessary to identify and conceptualize one of the main foundations of the construction of the New Latin American Constitutionalism. Thus, reflection starts from two essential questions for the theory of New Latin American Constitutionalism, in the first place: what is good living? And secondly: what are the human rights of good living? The general objective is to make some reflections on the well live, determine the Human Rights of the well live. The method used in the investigation phase was the Inductive.

KEYWORDS: Well live; Human rights; Constitutionalism; Latin America; Fundamentals.

\section{Introdução:}

São as mais recentes constituições da América do Sul que tratam a questão do bem viver e dos direitos humanos do bem viver, ou seja, a Constituição do Equador de 2008 e a Constutuição da Bolívia de 2009. A Constituição do Equador de 2008, aprovada na Assembléia Nacional Constituinte realizada na localidade de Montecristi, certamente é um

\footnotetext{
${ }^{1}$ Doutor em Direito (2000); Master em Direitos Humanos (1990); Ambos cursos realizados no Instituto de Direitos Humanos da Universidade Complutense de Madrid, Espanha. Realizou estagio pós-doutoral na Universidade de Santa Catarina entre 2012 e 2103. Desde 2001 professor do Programa de Pós-Graduação Stricto Sensu em Ciência Jurídica, Cursos de Mestrado e Doutorado, e do Curso de Graduação em Direito da Universidade do Vale do Itajaí (UNIVALI)- Santa Catarina. Da mesma maneira, desde 2015 professor do Programa de Pós-Graduação em Direito, Curso de Mestrado, da Universidade de Passo Fundo (UPF) - Rio Grande do Sul. E-mail: mleitegarcia@terra.com.br
} 
texto que trás consigo interessantes novidades, sobretudo sua relação do bem viver com os direitos humanos, um rol bastante inovador dos direitos, assim como a inclusão da natureza como sujeito de Direito. Da mesma forma, a Constituição da República Pluralista da Bolívia, como a do Equador, propõe a "refundação" do Estado, e cria uma nova ordem plurinacional, levando em consideração todas as étnias que formam sua sociedade plural, também inova no que se refere aos direitos humanos e a inclusão do paradigma do Bem Viver. Não resta dúvida que faz-se necessário ressaltar a importância fundamental para seus povos que representam as constituições em questão, uma vez que trata-se de uma verdadeira "refundação" de seus Estados, de suas nações, já que com o constitucionalismo tradicional de cunho liberal jamais foi possível abarcar e representar o total de seus cidadãos. Essas constituições anteriores uma vez que se tratavam de constituições do $f a z$ de conta, constitucionalismo simbólico nas palavras de Marcelo Neves (2007), serviam apenas para manter e perpetuar no poder as elites brancas e mestiças desses países. Elites estas que sempre estiveram aliadas ao poder econômico e aos interesses alienígenas como os das grandes corporações e do mercado mundial. Com governos populares e mais representativos a partir de interessantes processos constituintes - diga-se que exercício do processo constituinte originário de forma diferente do tradicional europeu e teorizado ainda pelo Abade Emmanuel Joseph Sièyes em 1789 -, finalmente foram aprovadas constituições mais autênticas e verdadeiramente feitas para essas nações. Um exemplo marcante é o da Bolívia: uma vez que com a chegada de Evo Morales ao cargo de Presidente da República e conseguinte estabilidade política, algo raro em sua história, somente logrado por um índio aymara e representante dos cocaleros (indígenas plantadores de coca). A forma de exercício do Poder Constituinte Originário nos países do Novo Constitucionalismo da América do Sul deve ser estudada e revista por nossos teóricos, assim como fizeram recentemente Gerardo Pisarello e Roberto Gargarella ${ }^{2}$.

Para sistematizar o tema aqui proposto, vamos dividir o mesmo em três momentos: um primeiro momento sobre o novo constitucionalismo latino-americano, seus inícios e seu atual momento, assim como e sobretudo iremos arrolar sobre suas novidades, entre as quais e as mais importantes encontra-se o fenômeno dos direitos humanos vistos a partir de um novo fundamento: o Bem Viver. Em segundo lugar vamos tratar do Bem Viver, seu conceito e seu fundamento a partir da cosmovisão indígena e de sua proposta mais ousada de criação de um novo paradigma interpretativo do Direito. Por último e em terceiro lugar trataremos sobre os

${ }^{2}$ Sobre o tema, veja-se os trabalhos de Gerardo Pisarello (2014) e Roberto Gargarella (2014). CONPEDI LAW REVIEW | QUITO - EQUADOR | v. 4 | n. 2 | p. 254 - 274 | JUL - DEZ | 2018 
direitos humanos no novo constitucionalismo latino-americano e sua relação com o Bem Viver.

\section{Novidades do constitucionalismo latino-americano}

A reflexão aqui proposta parte de duas perguntas essenciais para a teoria do Novo Constitucionalismo Latino-Americano, em primeiro lugar: o que é o bem viver? E em segundo lugar: quais são os direitos humanos do bem viver? Não podemos tratar da questão conceitual do bem viver sem levar em consideração os chamados direitos humanos do bem viver. A relação entre bem viver e direitos humanos é essencial para entendimento do Novo Constitucionalismo Latino-Americano. A nova teoria constitucional em questão é consequência dos processos políticos e sociais que irão desbordar em processos constituintes transformadores da vida social, política, econômica e cultural da Venezuela em 1999, do Equador em 2008 e da Bolívia em 2009. Os países em questão passaram por profundas transformações constitucionais como consequência de movimentos indígenas e organizações sociais e populares. Assim por tanto, as constituições em questão usam o termo refundação do Estado em matéria política, social, econômica, cultural, ideológica, filosófica e jurídica. Exatamente nessa "refundação" e valorização dos povos ancestrais vamos encontrar o conceito de Bem Viver e o fundamento dos Direitos Humanos do Bem Viver.

Um movimento de constitucionalização dos anseios dos movimentos sociais, mais autêntico e representativo que os que levaram às constituições anteriores, paralelo ao da integração regional dos países que formam a América do Sul - e provindo da chegada ao poder de governos mais democráticos -, é o do chamado provisoriamente de Novo Constitucionalismo Latino Americano. Entre outras muitas novidades e sobretudo a partir do que se convencionou denominar como novo paradigma de direito ambiental, ou nova visão ecocêntrica ou geocêntrica dos fenômenos que envolvem o Direito e o meio ambiente, visão esta que pretende superar o antropocentrismo de nossa era.

Uma das primeiras questões fundamentais do movimento do constitucionalismo ocidental será estabelecer suas bases conceituais. Na concepção de J.J. Canotilho existem muitos constitucionalismos, o inglês, o estadunidense, o francês, o alemão etc. (Bester, 2005, p. 28), além de várias etapas históricas do mesmo, mas em linhas gerais o professor português conceitua o constitucionalismo como “(...) a teoria (ou ideologia) que ergue o princípio do governo limitado indispensável à garantia dos direitos em dimensão estruturante da 
organização político-social de uma comunidade" (Canotilho, 1999, p. 47).

Da mesma forma que Canotilho, o espanhol Alfonso Ruiz-Miguel (2002, p. 9) estima o constitucionalismo como um movimento que se dá em etapas históricas. Marcadamente, pode-se falar de um constitucionalismo liberal-burguês, um constitucionalismo social de inícios do século XX e o chamado novo paradigma do neoconstitucionalismo do pós-segunda guerra mundial. Estes seriam os constitucionalismos moderno e contemporâneo; antes deles, porém pode-se afirmar que toda comunidade já tinha uma constituição em sentido empírico. É exatamente o que Canotilho (1999, p. 54) chama de constituição dos antigos, a constituição histórica e costumeira ainda não codificada em um só documento. A constituição em sentido normativo, escrita, é um produto das revoluções liberais burguesas do final do século XVIII que depois de derrubar o poder tradicional das monarquias absolutas busca legitimar o poder do novo paradigma da Modernidade e do Estado Liberal de Direito. A Constituição escrita moderna será uma nova maneira de fundamentar e limitar o poder do Estado, agora liberal e ainda baseado em uma democracia censitária e excludente. A partir das reivindicações dos trabalhadores e de seus defensores no século XIX e da universalização do sufrágio e consequentemente da adoção de uma democracia mais autêntica, com a adoção do constitucionalismo social do século XX, pode-se ver a transformação do constitucionalismo do Estado Liberal de Direito para o do Estado Social de Direito. A generalização dos direitos ou a inclusão social será então uma preocupação das constituições já do início do século XX a partir da chamada Constituição de Weimar, a Constituição da Alemanha de 1919.

Uma nova fase do constitucionalismo contemporâneo se dará a partir do final da II Grande Guerra Mundial, com a promulgação da chamada Lei Fundamental de Bonn, a Constituição da Alemanha de 1949 que influenciará marcadamente o constitucionalismo da segunda metade do século XX, assim como a Constituição da República Federal do Brasil de 1988 (Barroso, 2009, p. 40). Essa nova fase é denominada neoconstitucionalismo (Carbonell, 2009, passim., Carbonell; Jaramillo, 2010, passim. e Carbonell, 2007 passim.). Leciona Fábio de Oliveira (2009, p. 244) que:

Pode-se perceber o neoconstitucionalismo como o constitucionalismo insurgente a partir do término da II Grande Guerra. É fenômeno que engloba a legislação, a doutrina e a jurisprudência, ao lado de uma nova concepção da sociedade, do indivíduo, do Estado. Logo, em contagem cronológica, é movimento que computa em torno de sessenta anos, individualizada a idade de cada país, já que não desponta, no mesmo instante, em cada um. Há países mais velhos e mais jovens no neoconstitucionalismo. Experiências diversificadas, separadas, por vezes por décadas. 
Para Roberto Viciano Pastor e Ruben Martínez Dalmau (2012, p. 11-17), dois dos principais teóricos do Novo Constitucionalismo Latino Americano, tanto o constitucionalismo liberal como o social e o neoconstitucionalismo do pós-guerra de nada tem servido para os países do continente latino-am ericano enfrentarem seus verdadeiros problemas. Foram constitucionalismos meramente formais que na prática nada mudaram a situação política de práticas autoritárias e as desigualdades sociais no continente. A busca para dirimir seus verdadeiros problemas tem a sua esperança no chamado Novo Constitucionalismo LatinoAmericano.

Tal Novo Constitucionalismo é uma corrente complementar do movimento do neoconstitucionalismo do pós-guerra (Viciano; Martínez, 2012, p. 22), porém é inovador e voltado para a solução das questões da região (Viciano; Martínez, 2012, p. 25). Desta forma então pode-se destacar aqui cinco novidades nesta corrente: primeira, nova forma de exercício do Poder Constituinte superando a tradicional de cunho liberal; segunda, nova forma de democracia com ampla participação popular a partir da chamada democracia participativa e da introdução de novos mecanismos políticos de controle do parlamento; terceira, introdução de uma visão pluralista do Direito com a inclusão de outras jurisdições como a indígena; quarta, preocupação com a superação de uma cidadania meramente formal com a introdução de uma verdadeira e substancial democracia social que tem como objetivo diminuir as desigualdades sociais; e por último e em quinto lugar a mudança de paradigma do novo constitucionalismo no que se refere ao tratamento jurídico do meio ambiente no qual também deverá incluir uma jurisdição transnacional (Garcia, 2011, p. 152-174). Exatamente em esta quinta e última novidade increve-se o Bem Viver.

Na visão de Moraes e Marques Junior (2011, p. 249), “O Direito começa a despertar para a premência dessa revolução paradigmática, diante da crescente consciência ecológica, que se vê diante da ameaça de eliminação das condições mantenedoras da civilização e da vida humana neste Planeta". Assim, reivindicam propostas doutrinárias de substituição do paradigma antropocêntrico pelo paradigma geocêntrico, ou novo paradigma ambiental do Direto de proteção da natureza que se sobressaem nos novos textos do renovado constitucionalismo sul-americano. O novo paradigma ambiental ecocêntrico ou geocêntrico propõe produzir um giro epistemológico no Direito ao abandonar a concepção puramente antropocêntrica, a partir da qual foi edificado o Direito a partir do chamado Trânsito à modernidade, e reconhecer a natureza como sujeito de Direito (Moraes; Marques Jr., 2011, p. 249). 
Dentre as concepções aludidas por esses autores destacam-se as do argentino Ricardo Lorenzetti e do brasileiro Leonardo Boff. Par

a Lorenzetti (apud: Moraes; Marques Jr., 2011, p. 249): “Todo o edifício teórico da cultura ocidental tem sido construído sobre a base do indivíduo, utilizando os paradigmas da liberdade e da igualdade (...)”. E determina Lorenzetti que: “(...) A mudança atual está caracterizada por uma concepção menos antropocêntrica, isto é, a aparição da natureza como sujeito".

O catarinense Leonardo Boff ${ }^{3}$, mundialmente conhecido por ser um dos teólogos da libertação dissidente da igreja católica oficial, desde há algum tempo defende a Terra como sujeito de dignidade e de Direitos, com base em três argumentos: em primeiro lugar com apoio na atual comprovação científica de que a Terra é um organismo vivo; em segundo lugar por entender que a Terra participa da dignidade e dos direitos dos seres humanos e por ultimo com amparo na visão quântica da realidade que constata que tudo é energia em distintos graus de densidade (Moraes; Marques Jr., 2011, p. 250-251).

No mesmo sentido e como base do tratamento dado pelas constituições da Bolívia de 2008 e do Equador de 2009 e ainda pela Conferência Mundial dos Povos sobre as Mudanças Climáticas e os direitos da Mãe Terra, em Cochabamba na Bolívia, em abril de 2010, os povos latino-americanos indígenas, nações e organizações de diversa monta de todo o mundo proclamaram que os povos indígenas e os defensores do meio ambiente são filhos e filhas da Mãe Terra (Madre Tierra em espanhol ou "pachamama" no idioma quéchua); que a Mãe Terra é um ser vivo do universo que concentra energia e vida e que ela fornece sombra e vida a todos os seres vivos sem pedir nada em troca (Moraes; Marques Jr., 2011, p. 249-250).

Os espanhóis Roberto Viciano Pastor e Ruben Martínez Dalmau (2009, p. 38), a peruana Raquel Yrigoyen Fajardo (2006, p. 556-567) e o brasileiro Antônio Carlos Wolkmer (2013, p. 29-38) destacam que o Novo Constitucionalismo Latino Americano inicia-se entre outras constituições como a do Brasil de 1988, da Colômbia de 1991, do Peru de 1993, da Venezuela de 1999, mas que tem seu momento de autêntico constitucionalismo forte com as recentes constituições do Equador de 2008 e da Bolívia de 2009. A verdade é que os autores ainda não chegaram a um consenso de quando se inicia o fenômeno do chamado Novo

\footnotetext{
${ }^{3}$ Veja-se por exemplo os seguintes trabalhos: BOFF, Leonardo. A opção Terra: a solução para a terra não cair do céu. Rio de Janeiro: Record, $2009 \mathrm{~b}$. BOFF, Leonardo. A Terra: sujeito de dignidade e de direitos. $2010 \mathrm{~b}$. Disponível em < http://www.ecodebate.com.br/2010/04/22/a-terra-sujeito-de-dignidade-e-de-direitos-artigo-deleonardo-boff/ > Acesso em 31.03.2012. BOFF, Leonardo. Cuidar da Terra, proteger a vida: como evitar o fim do mundo. Rio de Janeiro: Record, 2010 a. BOFF, Leonardo. Ethos Mundial: um consenso mínimo entre os humanos. Rio de Janeiro: Record, 2009. 
Constitucionalismo Latino-Americano. Também não se trata de uma questão tão importante, mas por incluir a nossa Constituição brasileira de 1988 como que contém indícios de iniciar o novo constitucionalismo, fato que concordamos, destacamos a questão a partir de Raquel Yrigoyen Fajardo e na visão do professor da Universidade Federal de Santa Catarina Antonio Carlos Wolkmer. Para os professores da Universidade de Valencia, Roberto Viciano e Ruben Martinez Dalmau (2012, p. 13), o Novo Constitucionalismo Latino-Americano inicia-se com as Constituições da Colombia de 1991 e da Venezuela de 1999. Já na visão de Wolkmer e Yrigoyen o fenômeno haveria começado antes. Ambos professores falam em três ciclos sociais do novo constitucionalismo emergente em questão. A visão da professora Yrigoyen é muito bem descrita e reconstruida pelo professor Wolkmer. Para Antonio Carlos Wolkmer e Lucas Machado Fagundes (2011, p. 403-404) faz-se necessário sistematizar em três ciclos sociais para compreender os inícios do fenômeno chamado de Novo Constitucionalismo: Um primeiro ciclo social de carácter descentralizador, previsto nas Constituições do Brasil de 1988 e da Colombia de 1991, ao qual talvez pudéssemos acrescentar entre outras a Constituição do Paraguai de 1992. Um segundo ciclo social orientado por um constitucionalismo participativo e pluralista do qual a Constituição da Venezuela de 1999 é o seu exemplo emblemático e único. E um terceiro ciclo social, mais forte e autêntico, que é representado pala Constituições do Equador de 2008 e da Bolívia de 2009. Em nossa opinião, seguindo o professor Wolkmer (2013), consideramos importante a inclusão a Constituição da República Federativa do Brasil como integrante dos inícios do fenômeno, uma vez que não valoriza nossa democracia recente como e a inclusão de normas tão importantes no ordenamento constitucional pátrio como as que protegem as terras da nações indígenas brasileiras contra a ganância do poder econômico.

Também concordamos com a fala de Roberto Viciano no sentido de que trata-se, possivelmente, de uma quarta onda relativa ao movimento do constitucionalismo ocidental; ainda que o mesmo ainda careça de uma construção teórica mais sólida, essa quarta onda seria a seqüência de: uma primeira onda representada pelo constitucionalismo liberal, iniciado pelas revoluções burguesas; uma segunda onda representada pelo constitucionalismo social, iniciado a partir das revoluções socialistas; uma terceira onda pós segunda guerra mundial, iniciado pela constitucionalismo democrático que leva ao chamado Estado democrático e social de Direito. Novo paradigma do Direito chamado e teorizado de diferentes formas pelos autores como pós-positivismo jurídico, positivismo ético, garantismo jurídico, neoconstitucionalismo, etc. Claro que essa quarta onda ainda não está consolidada, mas 
estamos no início de uma era e não sabemos ainda se irá se consolidar através das décadas. Só o futuro tem a resposta, mas essa quarta onde seria o Novo Constitucionalismo LatinoAmericano e a questão do Bem Viver seria um dos seus importantes fundamentos.

\section{Reflexões sobre o conceito de bem viver}

O presente trabalho tem como objetivo principal fazer algumas reflexões sobre o bem viver, bien vivir ou buen vivir, seja como fundamento da construção do chamado novo constitucionalismo latino-americano, ou como elemento essencial para novo fundamento de legitimidade para os direitos humanos. Antes porém importante elucidar, como fazem Gudynas y Acosta (2011, p. 103) que este ideal em Equador se expressa como Buen Vivir em idioma espanhol (castelhano melhor dito, uma vez que optamos por respeitar os outros idiomas constitucionais da Espanha) ou sumak kawsay em idioma kichwa; enquanto que em Bolívia preferem a expressão Vivir Bien ou Bien Vivir (castelhano), ou ainda: suma qamaña em idioma aymara, ñandareko em idioma guarani ou sumak kawsay em idioma quéchua. Destacamos a expressão sumak kawsay, utilizada pelos quéchuas dos dois países, mas no presente trabalho usaremos indistintamente as expressões Bem Viver em português e Buen Vivir em castelhano.

O conceito de Bem Viver cobrará notoriedade a partir dos debates no seio da academia no Brasil e na América Latina, sobretudo e essencialmente a partir de sua positivação nas recentes constituições. É justamente desde a visão dos marginados pela história, os povos e nacionalidades indígenas, onde se pensa o Bem Viver como uma nova oportunidade para construir outra sociedade sustentada na comunidade, na convivência do ser humano em diversidade e em harmonia com a natureza, a partir do reconhecimento dos diversos valores culturais existentes em cada sociedade em particular em todo o planeta.

É correto então afirmar que as ideais do Buen Vivir se cristalizarão nas novas constituições da Bolivia e do Equador. Tal fenômeno se explica entre outros processos pela maior relevância outorgada aos saberes indígenas. Atuaram nesse sentido as próprias organizações dos povos indígenas, como por outro lado desde a teorização de acadêmicos, por um maior respeito desde vários espaços político-partidário às culturas ancestrais e novos vínculos com movimentos sociais (Gudinas; Acosta, 2011, p.106). Como em suas conversas e palestras explica Alberto Acosta $(2010 ; 2012)$ que as organizações indígenas jogaram papeies chaves, sejam nas ruas ou nas urnas, para essas mudanças de governo (Gudynas; Acosta, 
2011, p. 106). Ao mesmo tempo necessário se faz a busca de um caminho próprio, o fim da depedência intelectual, romper com as cadeias da eterna depedência, seja econômica e mesmo psicológica, com a valorização do que é nosso, o aumento de nossa autoestima. Iniciar em outras palavras um forte e verdadeiro processo de descolonização. Será o sociólogo e cientista político Aníbal Quijano quem lecionará sobre o tema.

Na discussão sobre o conceito de Bem Viver, o sociólogo Aníbal Quijano (2012, p. 55), recorda que - acreditamos ser de fundamental importância aqui mencionar essa reflexão do professor da Binghamton University de Nova Iorque - as populações indígenas ou "indiginizadas" sob a dominação colonial, em um primeiro momento e depois sob o controle de poder europeu ocidental, agora um fenômeno mundial de dominação cultural que ocorre a outros povos, não somente tem em comum as perversas formas de dominação e violência impostas por essa exploração colonial global de poder (Quijano as chama de colonialidad), como formas de resistência contra a opressão política e cultural. A resistência contra esse situação, segue Quijano, fez com que os chamados povos do sul, ou da periferia - como chamam os que descriminam -, compartam históricas aspirações comuns contra a dominação, a exploração e a discriminação. Estas são reivindicações históricas e conquistas de direitos fundamentais, conquistas que as forças conservadoras resistem em aceitar: "a igualdade social de indivíduos heterogêneos, a liberdade de pensamento e de expressão de todos esse indivíduos, a redistribuição igualitária de recursos, assim como o controle igualitário de todos os recursos, sobretudo no âmbito centrais da existência social" (Quijano, 2012, p 55).

Exatamente sobre a questão cabe aqui recordar as palavras de Michel Foucault (1999, p. 79) sobre a questão do racismo como forma de dominação. O racismo increve-se como mecanismo fundamental de poder, tal como exercem os Estado modernos e também é a condicão essencial que fundamenta a violência. A exploração colonial evidentemente levará em conta o racismo. Basta lembrar da famosa Controvérsia de Valladolid entre o dominicano Bartolomé de Las Casas e o teólogo Juan Ginés de Sepúlveda sobre a escravidão dos povos indígenas do continente americano (Pérez Luño, 1992).

Segue Quijano (2012, p. 55) no sentido de que as populações vítimas dos efeitos da exploração colonial global do poder (colonialidad) tem em seu cotidiano mais recente toda uma herança de resistência histórica de tão longo prazo. Aqui então entraria a questão do Bem Viver, quando Quijano argumenta no sentido de que estamos diante de uma necessidade urgente de aceitação de uma identidade histórica nova, no caso provinda de culturas autóctones, estruturalmente heterogênea que englobe a todos os povos, para qual seu 
desenvolvimento venha a produzir uma nova existência social liberada da dominação/exploração/violência, a qual é o coração da demanda principal do Foro Social Mundial: outro Mundo é possível!

Ainda que possamos ser ridicularizados atualmente pelos eurocêntricos - pelos que se consideram eternos donos do poder, donos da verdade e de uma suposta cientificidade -, Eugenio Raul Zaffaroni (2011, p. 113-114), em La Pachamama y el Humano, chama a atenção para o fato de que a ideia de madre tierra ou pachamama não nos chega de elaborações científicas, mas sim de manifestações do saber da cultura ancestral de sua milenar convivência com a natureza e esta incorporação no direito constitucional deve ser universal. Lembra Zaffaroni (Ibidem) que na revolucionária Assembléia Nacional Constituinte de Querétaro de 1917, quando como sabemos se inaugurou o constitucionalismo social originado na Constituição Mexicana, a mesmo foi ridicularizada pelos intelctuais da época, mas não podemos deixar de ver que as mesmas ideias de Direitos Sociais constitucionalizados foi adotada anos mais tarde em toda a Europa, sobretudo a partir da Constituição de Weimar de 1919.

Assim dessa maneira, segue argumentando Quijano (2012, p. 55) no sentido e em outros termos sobre o novo horizonte histórico que essa perspectiva o Bem Viver necessariamente é uma questão aberta que requer ser continuamente indagada, debatida e praticada.

Muito fácil averiguar que a questão do Bem Viver trata-se de um fenômeno que parte de um conceito plural, como foi visto, somente vendo sua questão terminológica. Tem sua especificidades de acordo com cada cultura. Se poderia falar de "buenos vivires" ou melhor ainda, nas palavras de Gudynas e Acosta, "buenos convivires". O Bem Viver não pode ser reduzido ao sumak kawsay dos quéchuas nem ao suma qamaña dos aymaras, uma vez que da mesma forma ideias similares encontram-se em distintas culturas indígenas, e também em algumas culturas mestiças ou criollas, como resultado da hibridização contemporâneas recentes (Gudynas, 2011). Da mesma forma segundo Gudynas e Acosta ${ }^{4}$ o conceito de Bem Viver tem como fonte também algumas tradições ocidentais que hão questionado diferentes pressupostos da modernidade dominante. Entre eles encontram-se posturas éticas de direitos fundamentais desenvolvidas nos últimos anos como as que reconhecem Direitos da Natureza,

\footnotetext{
${ }^{4}$ Para um estudo completo do conceito de Buen Vivir de Alberto Acosta veja-se: ACOSTA, Alberto. El Buen Vivir: Sumak Kawsay, una oportunidade para imaginar otros mundos. Barcelona: Icaria, 2013. Posteriormente lançada uma traducão para o português: ACOSTA, Alberto. O bem viver: uma oportunidade para imaginar outros mundos. Autonomia Literária, 2016. 258 p. 
Direitos das mulheres, a questão do feminismo, também Direitos de algumas minorias, como reação à dominação de base patriarcal, machista e antropocêntrica, assim como críticas às bases da justiça desde questionamentos em campos como os do desenvolvimento econômico ilimitado sem ter em conta o ser humano e a natureza, assim como o bem estar da sociedade como um todo. O desenvolvimentismo postulado pela economia tradicional e dominante desde Nicholas Georgescu-Roegen nos anos da década de 1970 vem recebendo críticas sobretudo por seus efeitos na natureza e na vida das pessoas por culpa de uma profunda falta de escrúpulos e de ética nas relações privadas, o que engloba entre outros assuntos questões como o atual consumismo exagerado de bens (e a consequente questão ambiental da fabricação de tantos bens - segunda lei da entropia ${ }^{5}$ ), a questão da obsolescência programada, além da destruição do planeta e própria sobrevivência do ser humano. A teoria do decrescimento sobre a qual Georgescu-Roegen (2012) é um dos pioneiros, assim como também um dos marginados pelo tradicionalistas da economia ocidental, são mal vistas e pouco consideradas e até ridicularizadas pelos donos da verdade da economia convencional.

Como foi dito as ideias e o ideal de Bem Viver serão formalizados (ou melhor que isso constitucionalizados) nas novas constituições do Equador (2008) e da Bolívia (2009). Como também foi mencionado, a partir de um conceito fundamentado nos saberes e nas sensibilidades de alguns povos ancestrais, ou seja, povos indígenas originários da América. No Equador a ideia de Bem Viver se expressa a partir do Sumak Kawsay em kichwa, que vinha sendo defendido e invocado por movimentos sociais e partidos políticos na década anterior ao processo constituinte de Montecristi (2007-2008). Na Bolívia, a ideia de vida buena também tem antecedentes nos povos ancestrais, sobretudo a partir da cultura aymara

\footnotetext{
${ }^{5}$ Para refutar a teoria simplista dos economistas tradicionais, Georgescu $(1996$, p. 179) se utiliza da segunda lei da termodinâmica, que é a lei da entropia. A termodinâmica é o ramo da física que estuda as relações entre o calor trocado e o trabalho realizado em um sistema físico, tendo em conta a presença de um meio exterior e as variações de pressão, temperatura e volume. A lei da entropia diz que em um sistema fechado, a desorganização tende a aumentar, e quando maior a desorganização mais alta a entropia. Segundo Georgescu em termos de termodinâmica o processo econômico tende a transformar matéria e energia de um estado de baixa entropia para um estado de alta entropia, que é a medida da energia indisponível em um sistema termodinâmico. O problema é que para a termodinâmica a energia existe de forma disponível ou livre, o que explica a existência de uma estrutura ordenada que depois de utilizada torna-se energia indisponível ou comprometida, que é dissipada em desordem. Georgescu cita como exemplo os combustíveis fósseis ainda amplamente utilizados, ou mesmo a energia nuclear. Os combustíveis fósseis, que são recursos livres, estão em harmonia com a natureza, e o montante de resíduos de energia desordenada e dissipada que são jogados na natureza é muito maior. Por causa da lei da entropia, afirma Georgescu-Roegen (1996, p. 180), a quantidade de energia dissipada por um sistema fechado aumenta cada vez mais. Quanto maior o desenvolvimento, quanto maior o consumo de bens industrializados, maior a quantidade de resíduos dissipados na natureza, ou seja mais alta a entropia, energia dissipada jogada na natureza. O planeta tem um limite para o consumismo exacerbado e irracional e para o desenvolvimento ilimitado. A termodinâmica ensina, segundo o autor romeno, que o custo de qualquer empreendimento industrial, em termos de entropia - por melhor que seja sua intenção, como na reciclagem -, é sempre maior que o produto. Sobre a lei da entropia veja-se Georgescu-Roegen (2012).
} 
desde seu suma qamaña (alguns críticos dizem que é uma formulação recente de intelectuais de essa etnia, mesmo que assim fosse, esse fato não invalida o conceito. Uzeda, 2009) e também de outras culturas como a partir do sumak kawsay quéchua, assim a ideia e o ideal de Bem Viver foi formulado também na Constituição da Bolívia. A forma de constitucionalização do Bem Viver nas duas constituições são diferentes. Veremos posteriormente essas diferenças.

$\mathrm{Na}$ busca de um conceito unitário para conceituar o Bem Viver em nosso estudo primeiramente é importante ver que dentre as teorias que procuram compreender a relação entre economia e ecologia (seria uma questão de sustentabilidade?), segundo o professor de economia da USP, José Eli da Veiga (2010, p. 109-111), há duas correntes claramente definidas e extremas, por isso absolutamente antagônicas: em primeiro lugar os teóricos que não veem dilema entre conservação ambiental e crescimento econômico (podemos considerálos como adeptos do desenvolvimento sustentável); e em segundo lugar os teóricos que de forma fatalista acreditam que conservação ambiental e crescimento econômico são duas questões inconciliáveis Existe ainda um terceira postura que procura abrir um "caminho do meio", mas que por enquanto somente faz parte da retórica político-ideológica (Veiga, 2010, p. 111). A segunda postura considera que a questão do crescimento econômico ilimitado versus conservação ambiental é de fundamental importância para o futuro da humanidade e do planeta. Segundo estes o crescimento econômico desenfreado é contrário não somente à conservação da natureza, mas sim contrário ao futuro da espécie humana. A primeira corrente considera os da segunda como caprichosos ou adeptos do modismo do ecologismo e também adjetivam os mesmos como "ecochatos" etc. Os da suposta terceira postura acabam sempre aceitando os argumentos da primeira. Tudo em nome do desenvolvimento econômico, do capital.

Assim, os adeptos da segunda postura já pensam no paradigma do biocentrismo ou geocentrismo. O homem inserido no biocentrismo, como parte do planeta conjuntamente com o seu entorno natural, o meio ambiente. O homem que ama seu ecossistema, sua casa (oikos, em grego), sua terra e seus companheiros de jornada: os animais. Por isso geocentrismo ou biocentrismo, ou ainda ecocentrismo. Como aos adeptos da primeira postura acreditam em um crescimento econômico ilimitado e creem que a tecnologia atual e supostamente futura tudo resolverá. Nada escapará à solução dos avanços tecnológicos do ser humano. Para seu consolo e certamente para adiar o problema, é que foi criado o conceito paliativo e falacioso do desenvolvimento sustentável. A Grande falácia de nossa Era. Entre eles se enquadram os 
economistas tradicionais, os conservadores, os neoliberais entre outros cientistas e leigos que trabalham pelo desenvolvimento capitalista desenfreado ${ }^{6}$.

Os defensores da segunda postura, os que consideram o crescimento econômico ilimitado absolutamente incompatível com a conservação ambiental, frequentemente são ignorados de modo que seus argumentos são dificilmente levados em consideração e sequer contestados. Ainda que seus adeptos sejam acusados de pessimismo (Carpintero, 2006, p. 177-185), a postura crítica é seguramente a mais relevante academicamente, porque não existe nenhuma evidência de como as questões da conservação ambiental e crescimento econômico poderiam ser conciliadas: predominam os indicadores que revelam tragédias ambientais atuais e futuras (Veiga, 2010, p. 109). Como ensina Veiga (2010, p. 109-111) não há um "caminho do meio" propriamente dito dentre as duas correntes apontadas e sim quando muito desdobramentos menos pessimistas da tese da impossibilidade do crescimento econômico contínuo, que termina sempre em simples retórica político-ideológica para justificar ou apaziguar as consciências dos que negociam e vendem a própria mãe, no sentido de que somos todos filhos da terra, la madre tierra ou pachamama dos povos originários dos Andes, que influenciou o Novo Constitucionalismo Latino Americano. A valorização da terra como a mãe de todos os seres vivos está dentro da cosmovisão dos povos indígenas originários das Américas. Além do que para ditos povos, segundo Fernando Huanacuni Mamani (2010, p. 15), em primeiro lugar está a vida como relação de equilíbrio e harmonia, pelo que o termo viver se aplica somente a quem sabe viver (bien vivir). Explica Huanacuni que os termos sumak kawsay (no idioma quéchua) ou suma qamaña (no idioma aymara) significam viver bem, mas não somente viver bem consigo mesmo, mas viver bem fazendo parte de toda a comunidade: "Es el camino y el horizonte de la comunidad, alcanzar el suma qamaña o sumak kawsay, que implica primero saber vivir y luego convivir”. Segue Huanacuni (2010, p. 15) no sentido de que "saber vivir, implica estar en armonía con uno mismo: estar bien o sumanqaña y luego, saber relacionarse o convivir con todas las formas de existencia". Estar bem consigo mesmo, em paz com sua consciência, para poder posteriormente se relacionar bem com os demais, preconiza Huanacuni. Viver em harmonia, consigo mesmo e com os demais e com a natureza, essa é a principal lição e o significado mais importante de Bem Viver nos ensinamentos de Fernando Huanacuni Mamani.

\footnotetext{
${ }^{6}$ Sem falar que o neoliberalismo é incompatível com o sistema democrático. A democracia torna-se uma falácia a partir do advento da ideologia neoliberal. A soberania popular serve somente para legitimar os poderosos no poder, quando as decisões mais importantes não são tomadas pelos representantes do povo. Sobre o tema veja-se entre outros: Antônio Avelãs Nunes (2016) e Zygmunt Bauman (1998) e Boaventura de Sousa Santos (2002).

CONPEDI LAW REVIEW | QUITO - EQUADOR | v. 4 | n. 2 | p. 254 - 274 | JUL - DEZ | 2018
} 
Para Gudynas (2011, p. 231) o Bem Viver significa uma nova forma de concepção da relação dos seres humanos com a natureza, de uma forma de assegurar ao mesmo tempo o bem estar das pessoas e a sobrevivência das espécies, das plantas, dos animais e de todo o ecossistema. Assim a adoção do Bem Viver como forma de vida requer uma transformação profunda na base de nossa sociedade capitalista da economia consumista e considerada arrogantemente inesgotável. Uma mudança de consciência, de paradigma. Não podemos mudar a sociedade sem mudar sua mentalidade. Assim como no dizer de Gregorio PecesBarba (1995), na sua fundamental lição sobre a mudança de mentalidade de um mundo medieval teocêntrico para o mundo moderno antropocêntrico, a mudança de mentalidade agora requer a passagem do antropocentrismo para uma nova forma de ver o mundo: seja geocentrismo ou biocentrismo. A consideração da madre tierra, pachamama, como a mãe de todos os seres vivos e da terra, deve ser considerada. Para acalmar o egoísmo (naturalmente humano) e o individualismo extremo da modernidade que leva aos seres humanos a cometer todas as espécies de barbaridades em nome das vantagens pessoais, somente é possível com a inclusão de uma nova percepção de mundo. No dizer de Eduardo Gudynas, o Bem Viver tem como objetivo romper com as visões clássicas do desenvolvimentismo tradicional, visões associadas a um interminável e ilimitado crescimento econômico, ao progresso perpétuo e linear interligado ao utilitarismo do antropocentrismo. Em uma de suas falas a professora Germana de Oliveira Moraes compara o Bem Viver e a cosmovisão andina ao nascimento do cristianismo na Palestina, que fazia parte da periferia do Império Romano. Bolívia e Equador são mal visto pela visão maniqueísta de um mundo liderados pelos auto-intitulados como vencedores, a visão dominante do ter acima do ser.

Para Leonardo Boff (2009 b) o Bem Viver é a categoria central da cosmovisão andina colocada como verdadeira alternativa para a humanidade como contrapartida e opção ao capitalismo competitivo e hostil aos menos favorecidos, este mesmo sistema do crescimento ilimitado em desequilíbrio com a natureza. Na mesma linha que Gudynas, Acosta e Huanacuni, preconiza Boff que o Bem Viver significa "(...) viver em harmonia consigo mesmo, com os outros, com a Pachamama, com as energias da natureza, do ar, do solo, das águas das montanhas, dos animais (...)", e o teórico catarinense matiza categoricamente "(...) sustentada por uma economia do suficiente e decente para todos, incluindo os demais seres" (grifo acrescentado). Tanto Leonardo Boff como Fernando Huanacuni falam que o Bem Viver está conectado com uma harmonia espiritual, sagrada ou divina, sobre a qual para incluir os não crentes preferimos falar em uma energia positiva que deve ser levada em consideração 
para entender a integralidade do conceito de Bem Viver. A questão da qualidade de aconfessionalidade do Estado moderno e contemporâneo deve ser mantida também no constitucionalismo, chamado novo e necessário, latino-americano, uma vez que a separação do Estado da religião, o Estado laico, certamente que é uma das grande conquistas da humanidade.

\section{Reflexões sobre os Direitos humanos do bem viver.}

Como preconiza Boaventura de Sousa Santos, na conclusão do livro "Para uma revolução democrática da justiça", no sentido de que "(...) a revolução democrática da justiça (...) é uma tarefa muito exigente, tão exigente quanto esta ideia simples e afinal tão revolucionária: sem direitos de cidadania efetivos a democracia é uma ditadura mal disfarçada" (Santos, 2011, p. 125). A reação conservadora sempre estará na ordem do dia, os reacionários seguem sua pronta manipulação e difamação agora sob o nome de que o que se deve combater é a ideologia bolivariana. Como ensina Albert O. Hirschman (1991) as retóricas da intransigência são intermináveis. A aliança histórica entre conservadores e liberais tem servido para negar direitos à maioria da população. Ocorre agora também na crise econômica do norte.

Muitos são os mitos acerca dos Direitos Humanos revisitados na atual doutrina dos Direitos Humanos, entre eles destacamos alguns que são discutidos por Gerardo Pisarello (2007) em sua reconstrução de dos direitos sociais e suas garantias. Da mesma forma que Pisarello, em tradução em nosso país David Sánchez Rubio (2014) revisita a questão geracional dos direitos humanos, que é portadora de alguns mitos. Os direitos humanos devem ser tratados como um conceito integral, a visão integral dos direitos humanos fundamentais é preconizada pelo professor Gregorio Peces-Barba. Os direitos sociais não podem ser considerados inferiores hierarquicamente nem mais débeis e nem posteriores ou dependentes dos direitos civis e políticos. Pisarello (2007) faz um interessantes estudos sobre todas essas questões. Os Direitos Humanos tratados como Direitos do Bem Viver podem ajudar a doutrina a superar essa dicotomia das gerações de direitos humanos/direitos fundamentais. A Constituição do Equador de 2008 trás uma contribuição muito interessante para o futuro da teoria dos direitos, uma vez que considera os Direitos Humanos como Direitos do Bem Viver e interligados por esse fator comum, perdem a divisão clássica em grupos ou gerações e assim são visualizados e considerados como íntegros, uma coisa só que 
deve levar ao conceito de sumak kaysaw. Esse é seu relacionamento com os Direitos Humanos como Direitos do Bem Viver.

As ideias de Bem Viver da Constituição do Equador de 2008 e da Bolívia de 2009 foram constitucionalizado de forma diferente: $a$ )- na Bolívia as referências ao Bem Viver, a ideia de Buena Vida, aparecem mais na base fundamentais do Estado. O Bem viver apresentase como princípios, valores e fins do Estado (art. $8^{\circ}$ da Const. Boliviana) onde como se lê: "asume y promueve como principios éticos-morales de la sociedad plural: ama qhila, ama llula, ama suwa (no seas flojo, no seas mentiroso ni seas ladrón), suma qamaña (vivir bien), ñandereko (vida armoniosa), teko kavi (vida buena), ivi maraei (tierra sin mal) y qhapaj ñan (camino o vida nobra). Se nota a influência multicultural quéchua, aymara e guarani. Esses princípios estão na mesma hierarquia que outros princípios constitucionais clássicos do neoconstitucionalismo ocidental tais como unidade, igualdade, inclusão social, dignidade da pessoa humana, liberdade, solidariedade, igualdade de gênero, bem estar social, responsabilidade, justiça social, etc. Todos incluídos como principios na Constituição da Bolívia de 2009. Assim na Bolívia o Bem Viver tem uma multiplidade de dimensões. O Bem Viver é bastante complexo, na Constituição da Bolívia esse ideal são princípios éticos-morais, mas não aparecem como direitos. b)- Na Constituição do Equador de 2009 o sumak kaysaw é apresentado em dois níveis: como fundamento da organização do Estado e da sociedade e como fundamento da execução dos chamados direitos do Bem Viver e então também como um conjunto de direitos, os Direitos Humanos do Bem Viver. O artigo 14 da Const. do Equador reconhece o direito da população de viver em um meio ambiente saudável e ecologicamente equilibrado que garantice a a sustentabilidade e o Bem Viver. Se considera de interesse público a preservação do meio ambiente. Os artigos anteriores (12 e 13) consideram Direitos Humanos do Bem viver a água e a alimentação. A água é um patrimônio nacional estratégico de uso público e essencial para a vida. A alimentação é um direito de todos. Além desses os Direitos do Bem Viver na Constituição de 2008 ainda incluem Saúde, Educação, Moradia, Comunicação, Energia, Cultura, Ciência, Lazer, Trabalho e Seguridade Social. A Constituição do Equador também consagra a natureza como sujeito de Direito disposto no artigo 71 que determina a proteção jurídica da pachamama. Emblemático é o caso do Rio Vilcabamba que estava sendo degradado por uma obra de construção de uma estrada na Província de Loja. Assim ocorreu um histórico primeiro julgamento que levou em consideração dos Direitos da Natureza, sendo o Rio Vilcabamba parte no processo e com sentença a seu favor.

CONPEDI LAW REVIEW | QUITO - EQUADOR | v. 4 | n. 2 | p. 254 - 274 | JUL - DEZ | 2018 


\section{Considerações Finais:}

Deve-se assim levar em consideração que os movimentos sociais de todas as montas, e sobretudo os movimentos sociais indígenas, certamente foram fundamentais nos processos constituintes originários levados a cabo tanto na chamada constituinte equatoriana de Montecristi como na constituinte boliviana de 2007 a 2008. Permitam-nos uma reflexão: que pode ser mais democrático que uma constituição feita a partir das reivindicações de autênticos e representativos movimentos sociais? Pela primeira vez na história desses países as culturas indígenas, os saberes de seus povos ancestrais, serão levados em consideração na refundação de suas sociedades. Para Gudynas e Acosta (2011) o Bem Viver se converteu em fertil campo de construção e sua analise permite abordar toda sua complexidade.

Não resta dúvida que o Bem Viver é um caminho em construção, um sendero en obras, para chegar a ser um coto vedado, ser incluído futuramente na esfera do indecidível como preconizam respectivamente os teóricos do Direito Ernesto Garzón Valdes e Luigi Ferrajoli (2008), uma norma topoi ou uma cláusula pétrea para o futuro do constitucionalismo. De acordo com Zaffaroni (2011), Gudynas e Acosta (2011, p. 71), é uma ideia em construção. Assim como todo o Novo Constitucionalismo Latino-Americano segue sendo uma ideia em construção, nas palavras de Roberto Viciano e Rubén Martínez Dalmau (2013, p. 49-55), o fenômeno constituinte latino-americano como é um constitucionalismo necessário. Necessidade para responder às novas aspirações de um futuro melhor, da construção de algo melhor, como resposta e contraponto de uma década tão ruim para América Latina como foram os anos 1990. Assim o constitucionalismo necessário característica-chave nas palavras de Viciano e Dalmau (2013, p. 52) - aproveitando os movimentos sociais, a eleição de governos populares e os anseios de uma nova de mudanças de nossas sociedades com vistas a um futuro melhor, mais humano e mais autêntico. Assim podemos então falar de algo nosso: o Bem Viver e o Novo Constitucionalismo LatinoAmericano.

\section{Referências:}


ACOSTA, Alberto. EI Buen Vivir en el camino del post-desarrollo: Una lectura desde la Constitución de Montecristi. Quito: Fundación Friedrich Ebert, 2010.

ACOSTA, Alberto. El Buen Vivir: Sumak Kawsay, una oportunidade para imaginar otros mundos. Barcelona: Icaria, 2013.

ACOSTA, Alberto. El complejo desafío de la construción del Estado Plurinacional. In: ARKONADA, Katu (Coord.). Un Estado, muchos pueblos: La construcción de la plurinacionalidad em Bolivia y Ecuador/ Barcelona: Icaria, 2012. p. 7-21.

AVELÃS NUNES, António José. O Neoliberalismo não é compatível com a Democracia. Rio de Janeiro: Lumen Juris, 2016.

BARROSO, Luís Roberto. Curso de Direito Constitucional contemporâneo: os conceitos fundamentais e a construção do novo modelo. São Paulo: Saraiva, 2009.

BAUMAN, Zygmunt. O mal-estar da pós-modernidade. Tradução de Mauro Gama, Cláudia Martinelli Gama. Rio de Janeiro: Jorge Zahar Ed., 1998.

BESTER, Gisela Maria. Direito Constitucional. Vol. 1: Fundamentos teóricos. São Paulo: Manole, 2005.

BOFF, Leonardo. A opção Terra: a solução para a terra não cair do céu. Rio de Janeiro: Record, $2009 a$.

BOFF, Leonardo. A Terra: sujeito de dignidade e de direitos. $2010 \mathrm{~b}$. Disponível em < http://www.ecodebate.com.br/2010/04/22/a-terra-sujeito-de-dignidade-e-de-direitos-artigo-deleonardo-boff/ > Acesso em 31.03.2012.

BOFF, Leonardo. Cuidar da Terra, proteger a vida: como evitar o fim do mundo. Rio de Janeiro: Record, $2010 a$.

BOFF, Leonardo. Ethos Mundial: um consenso mínimo entre os humanos. Rio de Janeiro: Record, $2009 b$.

CANOTILHO, José Joaquim. Direito Constitucional e Teoria da Constituição. Coimbra: Almedina, 1999.

CARBONELL, Miguel (org.). Neoconstitucionalismo(s). Madrid: Trotta, 2009.

CARBONELL, Miguel; JARAMILLO, Leonardo (orgs.). El canon Neoconstitucional. Madrid: Trotta, 2010.

CARBONELL, Miguel (org.). Teoría del Neoconstitucionalismo. Madrid: Trotta, 2007.

CARPINTERO, Oscar. La bioeconomía de Georgescu-Roegen. Barcelona: Montesinos, 2006.

FERRAJOLI, Luigi. La esfera del indecidible y la división de poderes. In: FERRAJOLI, Luigi. Democracia y garantismo. Madrid: Trotta, 2008. p. 102-110. 
FOUCAULT, Michel. Em defesa da sociedade: curso no Collège de France (1975-1976). Tradução de Maria E. Galvão. São Paulo: Martins Fontes, 1999. Título original: Il faut défendre la société.

FRANCO, Marina. Anticomunismo, subversión y pátria: construcciones culturalmente e ideológicas en la Argentina de los 70. In: CALANDRA, Benedetta; FRANCO, Marina (orgs.). La guerra fría cultural en América Latina: desafíos y límites para una nueva mirada de las relaciones intermericanas. Buenos Aires: Biblos, 2012. p. 195-210.

GARCIA, Marcos Leite. O processo de formação do ideal dos direitos fundamentais: alguns aspectos destacados da gênese do conceito. In: XIV Congresso Nacional do Conpedi, 2005, Fortaleza, CE. Anais. Disponível em:

http://www.org/manaus/arquivos/Anais/Marcos\%20Leite\%20Garcia.pdf >. Acesso em: 27 abr. 2009.

GARGARELLA, Roberto. La sala de máquinas: dos siglos de constitucionalismo en América Latina (1810-2010). Buenos Aires: Katz Editores, 2014.

GEOERGESCU-ROEGEN, Nicholas. O decrescimento: entropia, ecologia, economia. Apresentação e organização de Jacques Grinevald. Tradução de Maria J. P. Isaac. São Paulo. Editora SENAC, 2012. Título original: La décroissanance.

GEOERGESCU-ROEGEN, Nicholas. La ley de la entropía y el proceso económico. Tradução de Luis Gutiérrez Andrés. Madrid: Fundación Argentaria, 1996. Título original: The Entropy Law an Economics Proces.

GUDYNAS, Eduardo; ACOSTA, Alberto. El buen vivir o la disolución de la idea de progreso. In: ROJAS, Mariano (Coord.). La medida del progreso y el bienestar. Méjico: Foro Consultativo Científico y Tecnológico, 2011. p. 103-110.

GUDYNAS, Eduardo. Derechos de la naturaleza, muchos protagonistas, único sujeto. Temas para el debate 195. Madrid, 2011.

HIRSCHMAN. Albert O. Retóricas de la intransigencia. México: Fondo de Cultura Económica, 1991.

HUANACUNI MAMANI, Fernando. Vivirbien/Buenvivir: filosofía, políticas, estrategias y experiencias regionales. 4.ed. La Paz-Bolívia: Coordinadora Andina de Organizaciones Indígenas - CADI, 2010.

MORAES, Germana de Oliveira; MARQUES JUNIOR, William Paiva. O desafio da UNASUL de aproveitamento sustentável dos recursos energéticos e o novo paradigma ambiental. In: CADEMARTORI, Daniela; CADEMARTORI, Sérgio; MORAES, Germana de Oliveira; COELHO, Raquel. A construção jurídica da UNASUL. Florianópolis. Fundação José Arthur Boiteux/Editora da UFSC, 2011. p. 227-262.

NEVES, Marcelo. A constitucionalização simbólica. São Paulo: Martins Fontes, 2007. 
OLIVEIRA, Fábio de. Neoconstitucionalismo e Constituição Dirigente. In: QUARESMA, Regina; OLIVEIRA, Maria Lúcia de Paula; OLIVEIRA, Farlei. Neoconstitucionalismo. Rio de Janeiro: Forense, 2009. p. 239-266.

PECES-BARBA, Gregorio. Curso de Derechos Fundamentales: Teoría General. Madrid: Universidad Carlos III de Madrid, 1995.

PÉREZ LUÑO, Antonio Enrique. La polémica sobre el nuevo mundo. Los clásicos españoles de la Filosofía del Derecho. Madrid: Trotta, 1992.

PISARELLO, Gerardo. Los derechos sociales y sus garantías: elementos para una reconstrucción. Madrid: Trotta, 2007.

PISARELLO, Gerardo. Procesos constituyentes: caminos para la ruptura democrática. Madrid: Trotta, 2014.

QUIJANO, Aníbal. "Bien vivir": entre el "desarrollo" y la des/colonialidad del poder. Vento Sur. n. 122. p. 46-56. Mayo, 2012.

RUIZ MIGUEL, Alfonso. Una filosofia del derecho en modelos históricos: de la antigüedad a los inicios del constitucionalismo. Madrid: Trotta, 2002.

SÁNCHEZ RUBIO, David. Encantos e desencantos dos direitos humanos. Tradução de Ivone Fernandes, et al. Porto Alegre: Livraria do Advogado, 2014.

SANTOS, Boaventura de Sousa. Para uma revolução democrática da justiça. 3 ed. São Paulo: Cortez, 2011.

SANTOS, Boaventura de Sousa. Reinventar a Democracia. 2. ed. Lisboa: Fundação Mário Soares/Gradiva Publicações, 2002.

UZEDA VASQUEZ, Andrés. Suma qamaña. Visiones indígenas y desarrollo. Traspatios, CISO, UMSS, Cochabamba, n. p. 33-51.

VEIGA, José Eli da. Desenvolvimento sustentável: o desafio do século XXI. Rio de Janeiro: Garamond, 2010.

VICIANO PASTOR, Roberto; MARTINEZ DALMAU, Rubén. Fundamento teórico delnuevo constitucionalismo latinoamericano. In: VICIANO PASTOR, Roberto. Estudios sobre el Nuevo Constitucionalismo latinoamericano. Valencia: Tirant Lo Blanch, 2012.

VICIANO PASTOR, Roberto; MARTINEZ DALMAU, Rubén. Processo Constituinte Venezueleno no marco do Novo Constitucionalismo Latino-Americano. In: Wolkmer, Antonio Carlos; MELO, Milena Petters (orgs.). Constitucionalimo Latino-Americano: tendências contemporâneas. Curitiba: Juruá, 2013. p. 43-57.

WOLKMER, Antonio Carlos. Pluralismo crítico e perspectivas para um novo constitucionalismo na América Latina. In: Wolkmer, Antonio Carlos; MELO, Milena Petters (orgs.). Constitucionalimo Latino-Americano: tendências contemporâneas. Curitiba: Juruá, 2013. p. 19-42. 
WOLKMER, Antonio Carlos; FAGUNDES, Lucas Machado. Tendências contemporâneas do constitucionalismo contemporâneo: Estado plurinacional e pluralismo jurídico. Pensar Revista de Ciências Jurídicas. V. 16, n. 2. Jul/Dez 2011.

YRIGOYEN FAJARDO, Raquel. Hitos del reconocimientodel pluralismo jurídico y el Derecho indígena enlas políticas indigenistas y el constitucionalismo andino. In: BERRAONDO, Mikel (coord.). Pueblos indígenas y derechos humanos. Bilbao: Universidad de Deusto, 2006. p. 537-567).

ZAFFARONI, Eugenio Raúl. La pachamama y el humano. Buenos Aires: Colihue/Ediciones Madres de la Plaza de Mayo, 2011. 